\title{
Amazônia indígena: conquistas e desafios
}

\author{
EGON HECK, FRANCISCO LOEBENS \\ e PRISCILA D. CARVALHO
}

Nossas crianças brincam de guerrilheiro e militar; nossos rios estão contaminados; tivemos bebês com lábios leporinos; e até nossos cães e gatos estão nascendo deformados (Antonio Jacanimijov, coordenador geral do Conselho de Organizações Indígenas da Bacia Amazônica da Colômbia) ${ }^{1}$.

Não há lugar para os índios na hospedaria do neoliberalismo. A continuidade histórica dos povos indígenas sempre leva à ruptura com o sistema

(Paulo Suess, Luziânia, 8/8/03).

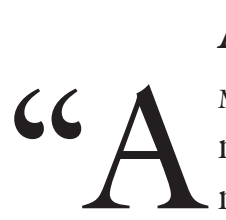

\section{Amazonizando}

MAZÔNIA", neste início de milênio, é uma das palavras mais bem ou mal ditas no planeta Terra. Sobre ela pesam afirmações como "pulmão do mundo", "floresta tropical de maior biodiversidade do planeta", "região que tem o maior rio da Terra", "inferno verde", "na Amazônia está quase um terço da água doce do mundo" etc. São razões suficientes para que se voltem, para essa região, olhares, radares, cobiças e preocupações de povos, países, organizações mundiais, empresas e cientistas. A Amazônia é tema indispensável desde as casernas mais nacionalistas até os pesquisadores mais preocupados com o futuro do nosso planeta, que ainda tem uma escora nessa região. Diz-se até que o futuro terá que passar necessariamente pela Amazônia.

Uma realidade bem menos conhecida e debatida no mundo é a grande e complexa sociodiversidade amazônica. Os povos, que nela foram se multiplicando aos milhares, constituíram complexas redes lingüísticas, intrincadas redes sociais e harmoniosos sistemas econômicos de trocas e fartura.

Nessa região vivem cerca de 180 povos indígenas, somando uma população de aproximadamente 208 mil indivíduos, além de 357 comunidades remanescentes de quilombolas e milhares de comunidades de seringueiros, ribeirinhos ou babaçueiros.

Neste texto será abordado um pouco desse mundo amazônico ocupado por povos indígenas nas mais diversas situações de relação e contato com as sociedades não indígenas, marcadamente ocidentais e européias. Ali vivem desde povos resistentes - também chamados ressurgidos - até os povos livres - isolados, que não têm contato algum com as sociedades nacionais, as quais, entre si, 
repartiram a grande bacia amazônica e nela desenvolvem as mais desencontradas e descontroladas políticas de ocupação e exploração.

Hoje, o avanço capitalista sobre a Amazônia é como uma fera, quase indomável. Motosserras e tratores fazem parte de programas oficiais de devastação. As grandes serrarias, que já exauriram o potencial madeireiro em outras regiões do mundo, agora seguem resolutas em direção à Amazônia, vestidas em peles de cordeiro, com o discurso da "exploração/ devastação sustentável", ostentando diplomas de "certificação verde" e com projetos de "auto-sustentabilidade" na Amazônia. Quem vivenciou a devastação em décadas passadas tem razões de sobra para prever novas catástrofes ambientais, atingindo particularmente os territórios indígenas. As mineradoras e companhias de petróleo estão afiando suas unhas para cavar cada vez mais fundo e mais rápido, para acumular ao máximo seu capital globalizado. Fazem pressão sobre o Congresso Nacional para que seja regulamentada a exploração mineral em terras indígenas. Há pedidos de pesquisa e exploração mineral sobre terras indígenas de toda a Amazônia.

Organizando-se para a sua sobrevivência e para a sobrevivência da região, há, hoje, uma luta articulada na Amazônia, constituída em grandes redes de resistência, conhecimento, reflexão e alianças que passam pela Coica - Coordenadora das Organizações Indígenas da Amazônia, pela Coiab - Coordenação das Organizações Indígenas da Amazônia Brasileira, pelo GTA - Grupo de Trabalho Amazônico e pelos recentes encontros do Fórum Social Pan Amazônico.

A Amazônia é palco de exploração, mas é também palco de inúmeras lutas de resistência e afirmação, como aquela pela defesa dos lagos contra os peixeiros predadores; do extrativista que, na reserva, gesta um novo pensamento coletivo de viver em meio à abundante natureza; dos cientistas que, pacientemente, aprofundam conhecimentos sobre a realidade amazônica e os devolvem à população. E há a teimosia diária dos povos indígenas em continuarem, dinamicamente, a viver do seu jeito.

\section{A Amazônia indígena}

A Amazônia, com sua natureza exuberante e ao mesmo tempo frágil, acolheu uma grande diversidade de povos, ao longo da história, no interior de suas matas e na beira dos rios. Depois da Conquista, em 1500, estes povos passaram a ser chamados, genericamente, de indígenas.

Os relatos dos cronistas das primeiras viagens de portugueses e espanhóis, ao longo dos rios Solimões e Amazonas, nos séculos XVI e XVII, fazem inúmeras referências à abundância de alimentos que encontraram em todas as povoações ao longo dos rios principais e de seus afluentes, à alta densidade populacional de numerosas "nações" que habitavam a região.

Projeções feitas a partir de documentos e de pesquisas arqueológicas estimam a população indígena, por ocasião da conquista, entre três e cinco milhões de pessoas, na Amazônia brasileira. 
A perspectiva histórica desses povos foi interrompida de forma brusca e violenta pelo projeto colonial que, valendo-se da guerra, da escravidão, da ideologia religiosa e das doenças, provocou na Amazônia uma das maiores catástrofes demográficas da história da humanidade, além de um etnocídio sem precedentes.

A participação da Igreja no processo, que teve nos jesuítas sua atuação mais marcante, presa à Coroa portuguesa pelo regime do padroado e movida pela missão de converter os índios ao cristianismo, foi incapaz de perceber o valor das culturas e, portanto, o projeto histórico desses povos. Mesmo assim, muitos missionários foram perseguidos, presos e expulsos porque denunciaram a violência e a injustiça praticadas contra os índios.

Segundo o antropólogo Moreira Neto, os índios passaram de maioria para minoria na Amazônia entre 1750 e $1850^{2}$. A violenta repressão à Revolução Cabana, que teve grande adesão indígena na primeira metade do século XIX, reduziu ainda mais a população nativa.

Muitos dos povos indígenas sobreviventes, que se refugiaram nas terras firmes dos altos dos rios, foram posteriormente alcançados pelo extrativismo da borracha, para o qual foram trazidas levas de nordestinos que, mantidos na condição de semi-escravos pelo sistema de aviamento, viram-se obrigados a invadir territórios indígenas pela força. Milhares de índios e nordestinos morreram para sustentar a opulência da elite da borracha.

Os massacres contra os povos indígenas voltariam a se repetir, já recentemente, a partir das décadas de 1960 e 1970, com as políticas de desenvolvimento e integração da Amazônia que começaram a rasgar a floresta com a abertura de estradas como a Transamazônica, a Belém-Brasília, a BR 364, a BR 174 e a Perimetral Norte. Povos como os Waimiri-Atroari, Yanomami, Arara, Parakanã, Cinta Larga e Nambikwara, entre muitos outros, foram duramente atingidos, inclusive por expedições de extermínio com participação do poder público.

Ainda hoje existem povos indígenas "livres", que continuam fugindo dos grandes projetos e das frentes colonizadoras, e que estão seriamente ameaçados de extinção, principalmente no estado de Rondônia e no sul do Amazonas.

Apesar da perseguição implacável, da escravidão, das guerras, das doenças criminosamente introduzidas e da imposição de um sistema que se orienta por parâmetros completamente diversos dos praticados pelos povos indígenas, eles não foram vencidos. Uma grande faixa carregada pelos índios da Amazônia na Marcha e Conferência Indígena 2000 chamava a atenção da sociedade para esse fato: "Reduzidos sim, vencidos nunca". A resistência indígena assumiu diversas formas e estratégias, que iam desde o confronto direto ou da guerra aberta até uma aceitação tácita da dominação, quando o contexto assim o exigia. Alianças interétnicas e com os setores marginalizados da sociedade brasileira, como ocorreu na Amazônia na primeira metade do século XIX, na Cabanagem, foram construídas para combater o poder opressor. 


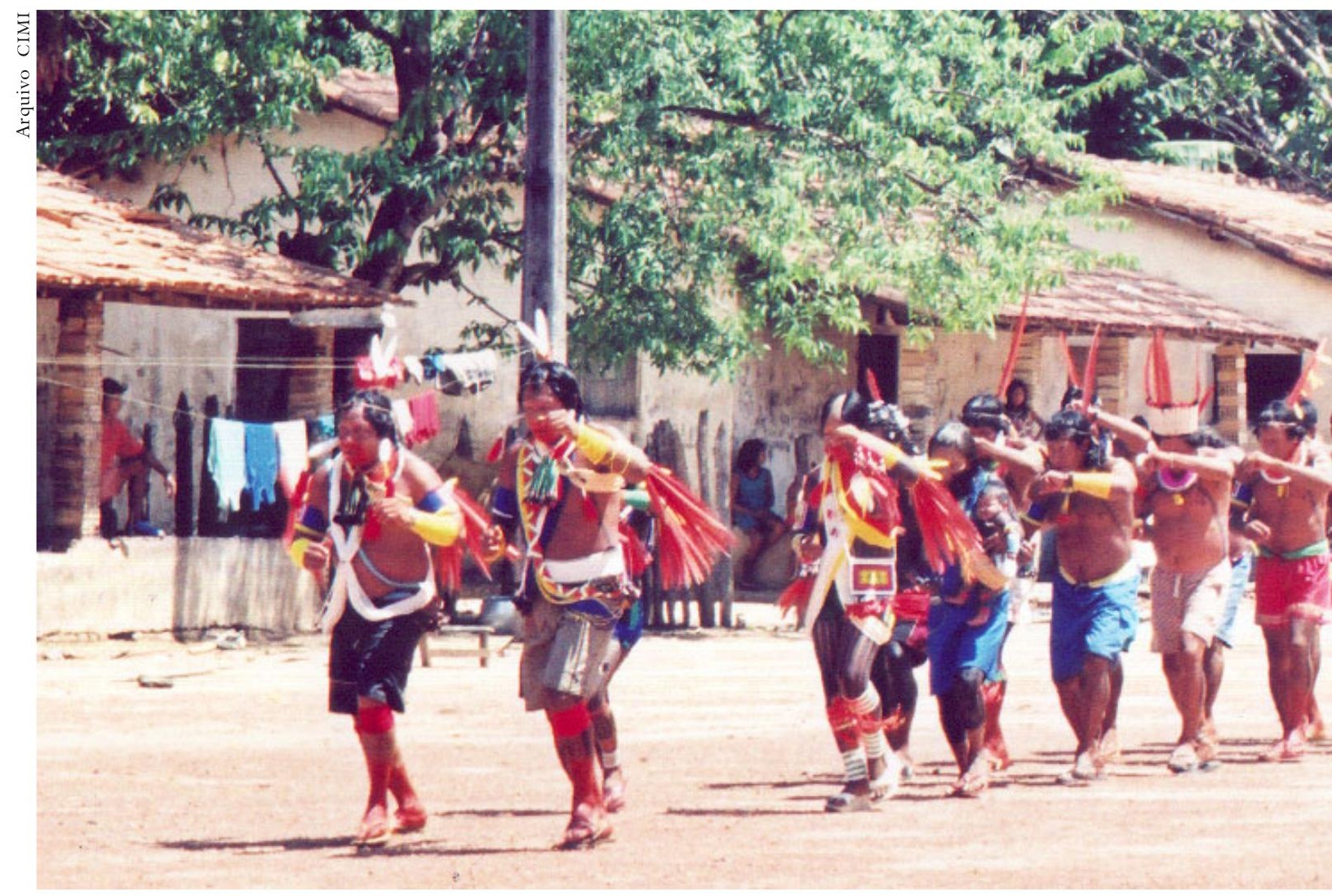

A década de 1970 marca um novo capítulo na luta e resistência indígenas. Os povos indígenas, apoiados sobretudo pela Igreja, por meio do Conselho Indigenista Missionário (Cimi), começaram a encontrar-se e a discutir seus problemas em grandes assembléias indígenas. Ocupando espaços nos meios de comunicação, denunciaram o projeto oficial de extermínio de uma Ditadura Militar que propunha o fim dos índios até o ano de 1998. Os povos indígenas conseguiram que a Constituição Federal de 1988 assegurasse seus direitos históricos à terra e o reconhecimento de suas organizações sociais. Constituíram variadas formas de articulação e organização para fazer avançar concretamente as conquistas legais.

Atualmente, tem-se conhecimento da existência de povos indígenas em todas as unidades da federação. São 235 povos que falam 180 línguas. Aproximadamente 180 povos indígenas (ou 77\% deles) vivem na Amazônia legal.

A tendência projetada pelas estimativas oficiais, que apontava para o extermínio total até 1998, começou a ser revertida a partir da década de 1970. Dados oficiais apontavam, nessa época, que a população indígena não ultrapassava cem mil pessoas. Desde então, a luta dos povos indígenas foi conquistando espaços territoriais que permitiram o crescimento demográfico, e os próprios índios começaram a apresentar levantamentos demográficos, desmentindo os dados oficiais que subestimavam a população ${ }^{3}$. Povos que mantinham a sua identidade oculta sentiram-se encorajados a assumi-la publicamente ${ }^{4}$ e as estatísticas também começaram a registrar uma numerosa população indígena nos centros urbanos. 


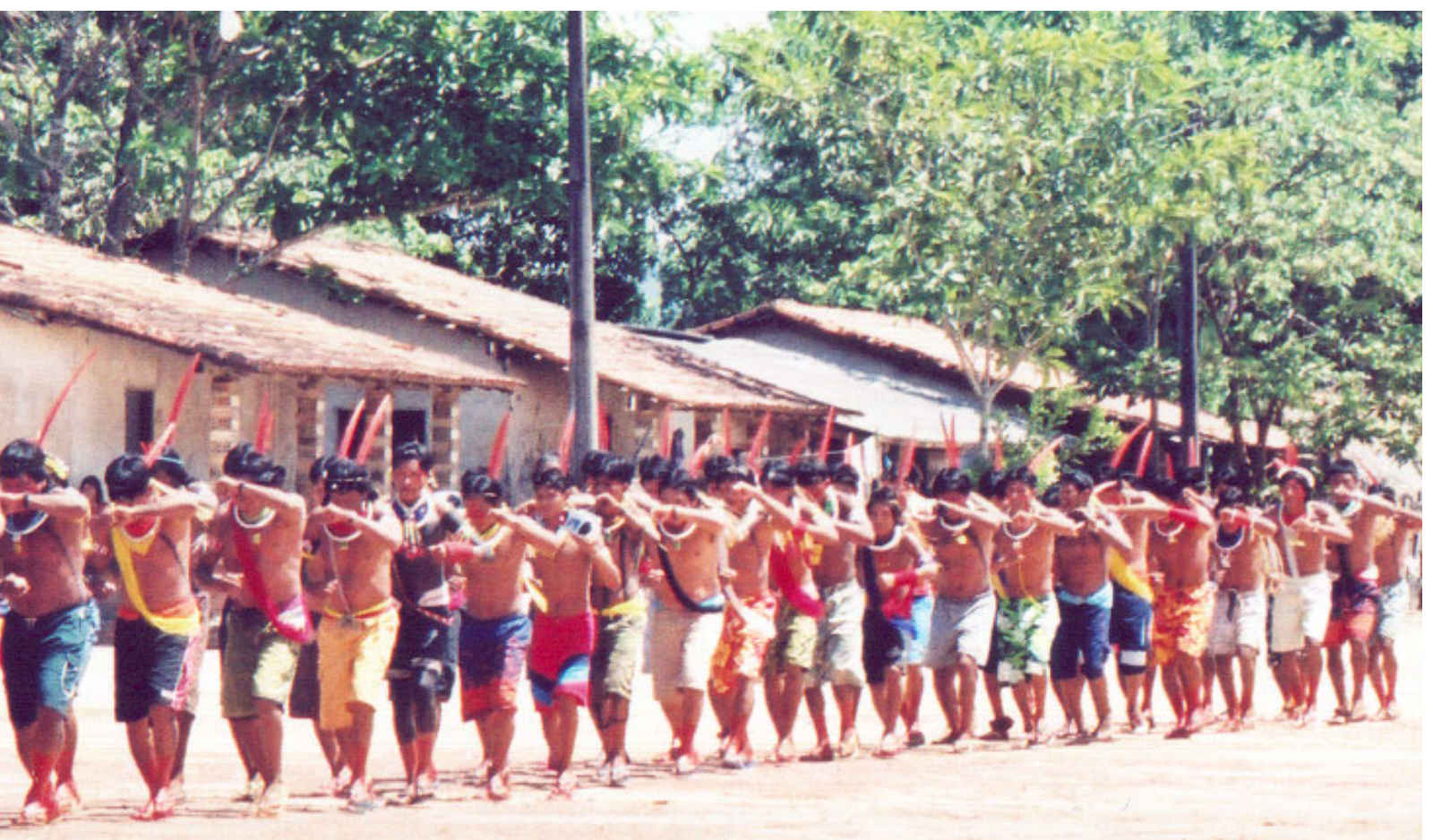

Esses fatores contribuíram decisivamente para que a população indígena registrada pelo levantamento do IBGE em 2000 somasse 734.131 pessoas, das quais 350.834 localizadas nas terras indígenas e 383.297 nas cidades. Esses dados, em algumas regiões do país, subestimam o número de índios localizados em suas terras. Em Roraima, por exemplo, o DSEI-Leste ${ }^{5}$, administrado pelo Conselho Indígena de Roraima (CIR), tem 25.694 índios cadastrados, sem considerar os Yanomami e Waimiri-Atroari, localizados naquele estado, enquanto os números do IBGE apontam, em todo o estado, 22.331 indígenas.

A região amazônica concentra 59,43\% dos índios brasileiros que vivem em terras indígenas e apenas 16,09\% dos indígenas que vivem nas cidades, distribuídos pelos estados que compõem a região da seguinte forma:

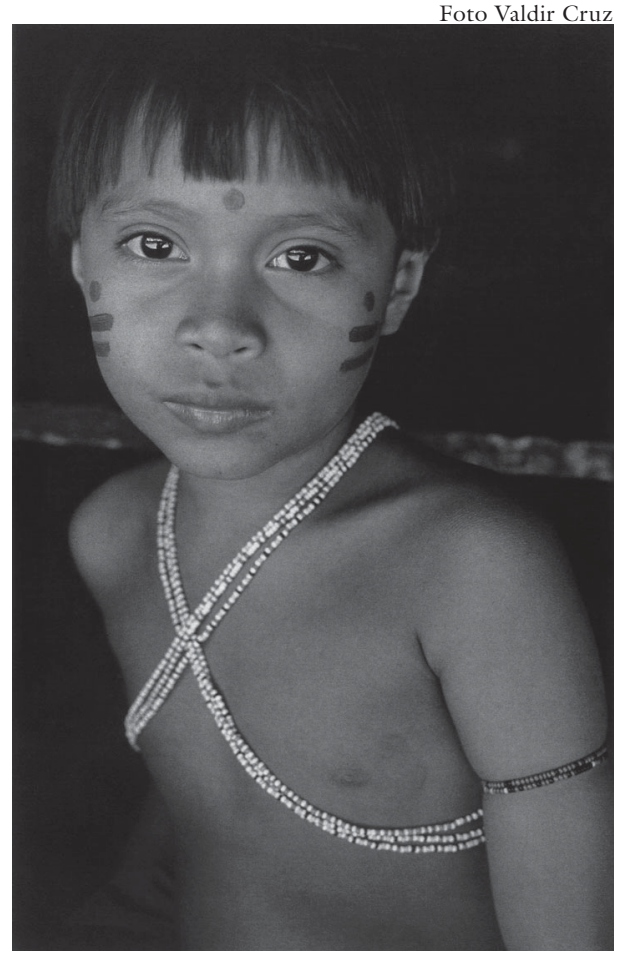

Ritual de iniciação do povo Kayapó na aldeia Gorotire, em Cumaru (PA); e jovem adolescente Yanomami. 


\begin{tabular}{|c|c|c|c|}
\hline \multirow[b]{2}{*}{ UF } & \multicolumn{3}{|l|}{ População } \\
\hline & $\begin{array}{l}\text { Nas terras } \\
\text { indígenas }\end{array}$ & $\begin{array}{c}\text { Nas } \\
\text { cidades }\end{array}$ & Total \\
\hline 1. Amazonas (AM) & 94.608 & 18.783 & 113.391 \\
\hline 2. Roraima (RR) & 22.331 & 5.797 & 28.128 \\
\hline 3. Mato Grosso (MT) & 21.848 & 7.348 & 29.196 \\
\hline 4. Pará (PA) & 25.962 & 11.718 & 37.681 \\
\hline 5. Maranhão (MA) & 19.535 & 8.036 & 27.571 \\
\hline 6. Acre (AC) & 6.911 & 1.098 & 8.009 \\
\hline 7. Tocantins (TO) & 7.153 & 3.428 & 10.581 \\
\hline 8. Rondônia (RO) & 6.460 & 4.223 & 10.683 \\
\hline 9. Amapá (AP) & 3.714 & 1.258 & 4.972 \\
\hline Total & 208.522 & 61.689 & 270.211 \\
\hline
\end{tabular}

Os dados do Censo do IBGE de 2000, relativos à população indígena, ainda que não sejam precisos, também chamam a atenção para uma outra realidade, que é a expressiva presença de índios nas cidades, o que coloca novos desafios para o movimento indígena e seus aliados e para o Estado, especialmente no que se refere ao atendimento à saúde e à educação diferencidas. Tendo percebido essa realidade ha vários anos, o Cimi, juntamente com as Igrejas locais, começou a constituir equipes em Manaus, Boa Vista e São Paulo, as quais, no dia-a-dia com essas populações indígenas, vão construindo caminhos que respondam a esses novos desafios.

É significativo constatar que na região Amazônica, de acordo com os dados do IBGE, vivam $60 \%$ dos índios residentes no interior e apenas $16 \%$ dos que se encontram nos centros urbanos. Considerando que, em extensão, mais de 98\% das terras indígenas estão localizadas na Amazônia, podemos afirmar que existe uma relação direta entre a migração e a quantidade de terra e o nível de preservação dos recursos naturais nelas existentes. A migração indígena para as cidades é bem maior nas regiões em que os índios tiveram seus espaços territoriais reduzidos a ínfimas porções e ambientalmente degradados.

Apesar dessa promissora reação indígena revelada pelas estatísticas populacionais, dados de 1995 do Instituto de Medicina Tropical de Manaus atestam que a expectativa de vida média dos índios é de apenas 42,6 anos, enquanto de acordo com a Organização Mundial de Saúde, os brasileiros, de modo geral, vivem em média 67 anos.

\section{Demarcação e garantia das terras indígenas}

As terras tradicionalmente ocupadas pelos povos indígenas foram reconhecidas pela Constituição Federal de 1988 como sendo de posse permanente desses povos, com direito ao usufruto exclusivo das riquezas naturais nelas existentes. Constitucionalmente, este é um direito inalienável, indisponível e imprescritível. 
Segundo os dados do Cimi, são conhecidas 841 terras indígenas no Brasil, encontrando-se na seguinte situação jurídica em termos de demarcação ${ }^{6}$.

\begin{tabular}{|c|c|c|c|c|}
\hline \multirow[b]{2}{*}{ Situação } & Brasil & \multicolumn{2}{|c|}{ Amazônia } & \multirow[b]{2}{*}{$\%$} \\
\hline & №. de Terras & $\%$ & №. de terras & \\
\hline Registradas & 311 & $36,98 \%$ & 231 & $46,30 \%$ \\
\hline Homologadas & 58 & $6,90 \%$ & 42 & $8,41 \%$ \\
\hline Declaradas & 41 & $4,88 \%$ & 27 & $5,41 \%$ \\
\hline Identificadas & 36 & $4,28 \%$ & 16 & $3,20 \%$ \\
\hline A Identificar & 132 & $15,70 \%$ & 100 & $20,04 \%$ \\
\hline Sem Providências & 229 & $27,23 \%$ & 5 & $1,00 \%$ \\
\hline Reservadas/Dominiais & 34 & $4,04 \%$ & 78 & $15,64 \%$ \\
\hline Total & 841 & $100 \%$ & 499 & $100 \%$ \\
\hline
\end{tabular}

Esses dados revelam que, no Brasil, 36,98\% das terras indígenas tiveram, até o momento, concluído o procedimento administrativo de demarcação, que se encerra com o registro no cartório do município (ou dos municípios) onde está localizada a terra indígena e no Departamento de Patrimônio da União.

Das 499 terras indígenas existentes na Amazônia ${ }^{7}, 46,3 \%$ concluíram o procedimento demarcatório com o registro no Departamento do Patrimônio da União e nos Cartórios de Registro de Imóveis dos Municípios onde estão localizadas. 33,56\% do total das terras, ou cem delas, sequer tiveram seus limites declarados através de Portaria do Ministro da Justiça.

Por outro lado, o número de terras sem providências, isto é, que são contabilizadas pelos povos indígenas e por entidades indigenistas, mas que não constam da lista oficial da Fundação Nacional do Índio (Funai), é menor na Amazônia (1\%) do que na média geral do país $(27,23 \%)$.

No que tange à homologação das terras indígenas, o ano de 2003 foi marcado, no Brasil, pelo primeiro caso de redução de uma terra indígena no ato de sua homologação. Trata-se da terra Baú, do povo Kayapó, no Pará, e o fato pode significar um precedente para a redução de outras terras indígenas onde haja pressões dos setores contrários à demarcação da área. Na terra Baú, a redução ocorreu por meio da celebração de um Termo de Conciliação e Ajuste de Conduta, aceito pelos Kayapó - assistidos pela Fundação Nacional do Índio - em troca de um milhão e duzentos mil reais. A terra indígena foi reduzida em trezentos mil hectares.

O Cimi e diversas entidades consideram o procedimento ilegal por ferir o S 6. ${ }^{\mathrm{o}}$ do art. 231 da Constituição Federal de 1988, que determina a nulidade de todos os atos que tenham por objeto a ocupação, o domínio e a posse das terras indígenas. 


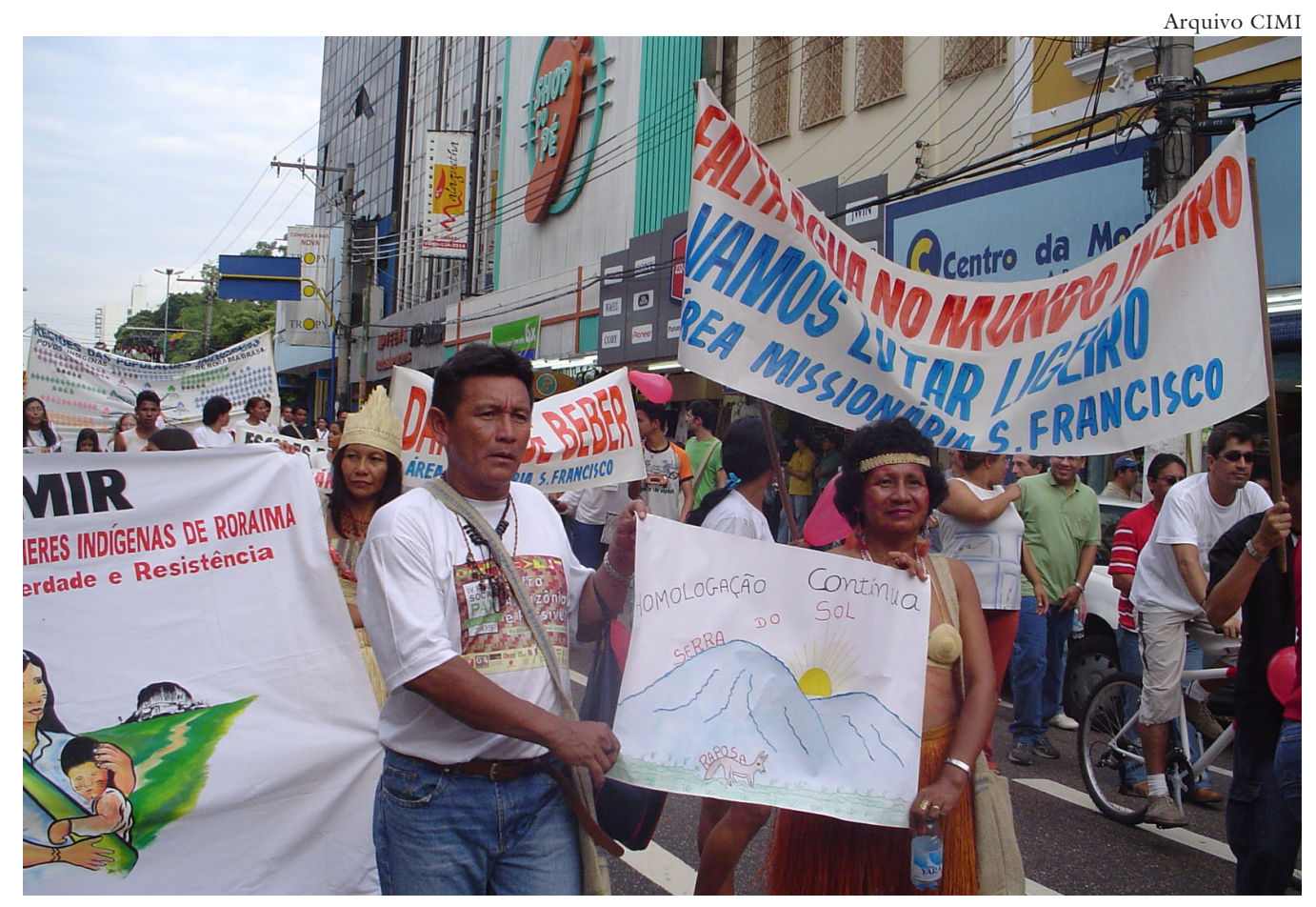

Manifestação de povos indigenas durante o IV Fórum Social Pan Amazônico, 2005.

\section{Raposa Serra do Sol}

Das terras indígenas que ainda não tiveram o procedimento demarcatório concluído na Amazônia, uma, em particular, chama a atenção pelos transtornos criados pelo governo federal e pelas autoridades locais para sua regularização. Trata-se da terra indígena Raposa Serra do Sol, em Roraima, com extensão de 1.678.800 hectares, habitada por quinze mil índios dos povos Macuxi, Wapichana, Ingaricó e Taurepang. O governo estadual, para obstruir a demarcação, criou o município de Uiramutã em 1997, quatro anos depois da conclusão da identificação da terra como indígena, pela Funai. O município foi criado a partir de uma antiga currutela ilegal de garimpo, encostada a uma maloca e fica, portanto, no interior da terra indígena.

O Projeto Calha Norte, que vem desrespeitando os direitos indígenas desde a sua criação, percebendo que o município poderia favorecer aos seus objetivos de atrair mais gente para a fronteira, construiu um quartel naquele município, em 2000.

A Portaria do Ministro da Justiça, publicada no Diário Oficial no final de 1998, declarou os limites da terra indígena, mas o impasse político continuou existindo. Fernando Henrique Cardoso protelou por três anos a assinatura do Decreto de Homologação.

Neste ínterim, os setores anti-indígenas contestaram judicialmente a demarcação de Raposa Serra do Sol em área contínua. Por meio de uma Ação Popular que tem entre seus signatários o senador Mozarildo Cavalcanti (PPS-RR) - soli- 


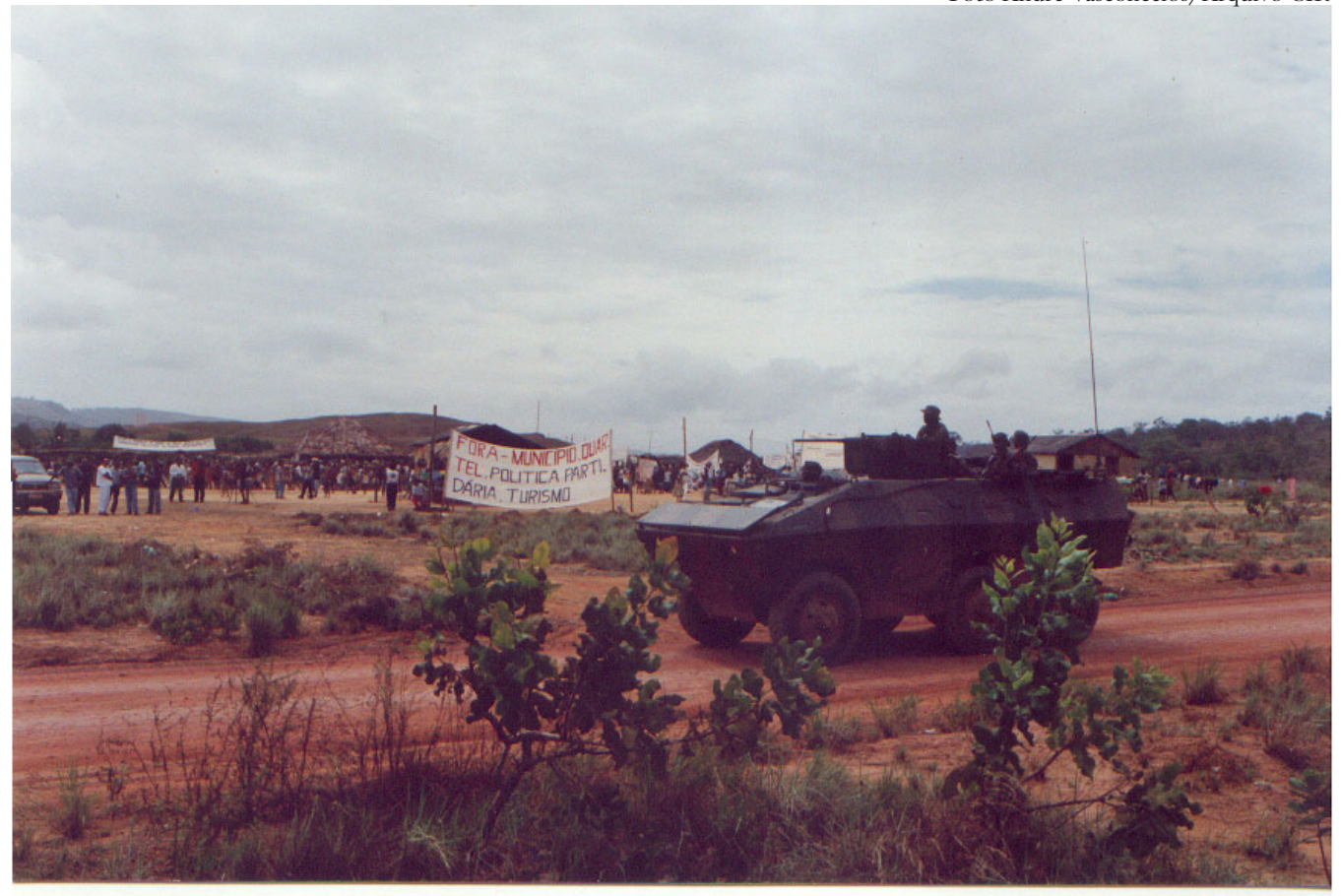

Festa do Ou vai ou racha na reserva Raposa Serra do Sol do povo Makuxi, em abril de 2002.

citam que a homologação seja de forma descontínua, excluindo-se o município de Uiramutã, os imóveis titulados antes da Constituição de 1934 e as plantações de arroz que se instalaram dentro da terra indígena.

O atual governo, de Luiz Inácio Lula da Silva, que assumiu com o compromisso de demarcar e garantir as terras indígenas, mantém a mesma indefinição em relação à Raposa Serra do Sol, promovendo em torno do Decreto de Homologação, que é um mero ato administrativo, um espaço de disputa inócuo e desgastante.

Sob a justificativa da governabilidade, o governo Lula investiu na ampliação de alianças. Neste contexto, o então governador de Roraima, Flamarion Portela, filia-se ao Partido dos Trabalhadores (PT), e a bancada de Roraima no Congresso, que é declaradamente contrária à homologação contínua de Raposa, passa a compor a base de sustentação do governo.

Em paralelo às questões políticas, correm as disputas judiciais: no final de dezembro de 2004, mais uma vez os entraves jurídicos para a homologação em área contínua estavam solucionados, e mais uma vez o Governo Federal deixou passar a possibilidade de homologar Raposa Serra do Sol. Em janeiro de 2005, uma decisão do STF voltou a suspender a Portaria 820, do Ministério da Justiça. A decisão não é definitiva, e o impasse deverá ser solucionado por meio de votação no pleno do Supremo em suas próximas reuniões, que ocorrem a partir de fevereiro de 2005.

A indefinição e o confortável jogo de troca de responsabilidades entre o executivo e o judiciário, que atende aos interesses anti-indígenas da elite de 
Roraima, gerou um quadro permanente de violência entre índios e não-índios. No início de 2004, foram seqüestrados três missionários e, no mês de novembro, os fazendeiros atearam fogo a três comunidades indígenas de Raposa (aldeias Jawari, Homologação e Brilho do Sol) e ao retiro São José.

Os indígenas dos povos que vivem em Raposa Serra do Sol, organizados em torno do Conselho Indígena de Roraima (CIR) continuam buscando caminhos para a definição de suas terras. Em março de 2004, CIR e a Rainforest Foundation, dos EUA, denunciaram o Estado brasileiro à Organização dos Estados Americanos (OEA) por violação aos direitos indígenas. Solicitaram à OEA que recomendasse ao governo brasileiro a homologação da Terra Indígena Raposa Serra do Sol em área contínua, da forma como foi demarcada. A resposta do organismo internacional continua em aguardo.

"Como esgotamos todos os recursos possíveis no Brasil, recorremos à OEA, onde protocolamos e formalizamos a denúncia, para defender os direitos humanos das comunidades indígenas da Raposa Serra do Sol”, relata Joênia Wapichana, advogada indígena. "Alertamos para a violação pelo Estado brasileiro de vários artigos da Convenção Americana dos Direitos Humanos", conta a advogada. A convenção foi ratificada pelo Brasil em 25 de setembro de 1992 e, portanto, tem força de lei interna.

Em 6 de dezembro de 2004, após os episódios de violência, a Comissão Interamericana de Direitos Humanos recomendou ao Governo do Brasil quatro medidas: 1. proteger a vida e a integridade pessoal dos povos indígenas Ingaricó, Macuxi, Patamona, Taurepang e Wapichana, respeitando sua identidade cultural e sua especial relação com o território ancestral; 2. assegurar que os beneficiários possam continuar a habitar suas comunidades, sem nenhum tipo de agressão, coação ou ameaça; 3 . abster-se de restringir ilegalmente o direito de livre circulação dos membros dos povos indígenas Ingaricó, Macuxi, Patamona, Taurepang e Wapichana; 4. investigar séria e exaustivamente os fatos que motivaram o pedido de medidas cautelares.

De acordo com a recomendação, essas medidas devem ser decididas em consulta com os povos indígenas da Raposa Serra do Sol e o Brasil teria um prazo de quinze dias para informar a CIDH sobre quais delas foram adotadas.

"Está na hora do Brasil e, principalmente, de Roraima, aceitarem e trabalharem com a realidade indígena. Raposa Serra do Sol é muito mais que palmos de chão, é a vida de vários indígenas vítimas de tanta violência”, afirma Joênia Wapichana.

\section{Ocupantes não-índios, exploração das terras e projetos governamentais}

As terras indígenas na Amazônia legal, como no restante do país, são extremamente vulneráveis, invadidas constantemente por madeireiros, garimpeiros, peixeiros, rizicultores, fazendeiros, posseiros, biopiratas e outros aventureiros 
em busca do lucro fácil. No sul do Pará, na terra indígena Kayapó, por exemplo, existe contrabando de mogno. Em Rondônia, terras indígenas continuam sendo arrasadas pela exploração ilegal de madeira e pelo garimpo. Em Roraima, na terra indígena Raposa Serra do Sol, fazendeiros praticam a monocultura do arroz usando agrotóxicos que envenenam os rios e os solos e provocam a mortandade dos pássaros. A terra indígena Yanomami até hoje não está livre da invasão garimpeira.

A mais recente ameaça às terras indígenas na Amazônia vem da expansão do agronegócio, especialmente da monocultura da soja. No Mato Grosso, essa cultura é mais antiga; no sul do Amazonas, na região de Lábria, as plantações mais recentes já são consolidadas e, nas terras de Roraima, os fazendeiros já têm prontos estudos de viabilidade e pretendem iniciar o plantio.

As conseqüências da expansão do agronegócio na região Amazônica estão relacionadas à degradação ambiental e à ameaça aos territórios já conquistados ou ainda reivindicados pelas populações tradicionais, entre elas os povos indígenas.

Mas o problema vai além, e está ligado ao modelo de desenvolvimento que o Estado brasileiro continua adotando não apenas para aquela região, mas para todo o país: um desenvolvimento voltado para atender as necessidades do mercado externo, no qual os recursos naturais sofrem toda a sorte de pressão e no qual as diversidades culturais e étnicas do país são vistas como entrave à expansão dos lucros ou à elevação do saldo da balança comercial.

Em 2004, voltou à cena o debate sobre a regulamentação da exploração mineral em terras indígenas, estimulada por casos de violência como aqueles ocorridos na reserva Roosevelt, em Rondônia, e pelo interesse de mineradoras brasileiras e estrangeiras na exploração de minérios. Prevista desde a Constituição de 1988, a exploração ainda depende de lei complementar para poder ser realizada no Brasil.

A regulamentação da exploração mineral sem dúvida trará impactos para os povos da Amazônia, já que suas terras estão, desde a década de 1980, loteadas com pedidos de pesquisa e exploração feitos por mineradoras nacionais e multinacionais.

Outra forma de ocupação de terras indígenas é aquela promovida por projetos governamentais e privados, como a construção de hidrelétricas (Belo Monte e Tucuruí, por exemplo), hidrovias, linhas de transmissão de energia, projetos militares, criação de municípios e de unidades de conservação, para os quais os limites das terras indígenas não têm o menor significado.

\section{Índios, militares e fronteiras}

A presença de povos e terras indígenas na faixa de fronteira (que atualmente é definida como uma faixa imaginária de terra, com $150 \mathrm{~km}$ de largura, a partir das fronteiras terrestres do país) tem sido contestada principalmente por setores militares. $\mathrm{O}$ discurso de ameaça à segurança e à soberania nacional é reciclado 
nos diferentes momentos da nossa história, sem que haja mudanças substanciais nos atores e questões envolvidas.

É oportuno lembrar o pensamento que tiveram a esse respeito o brigadeiro Camarão, idealizador do trinômio “Índios-Funai-Missões”, que entendia que os índios seriam úteis para a defesa das fronteiras do país, e do brigadeiro Protásio Lopes que, em 1979, sustentava um discurso segundo o qual os índios eram vistos como "quistos étnicos" e um perigo para a segurança nacional.

A FAB procura ajudar os missionários, o seu intento é o aculturamento do indígena, a sua catequese, a sua evangelização, com o fim religioso, mas que na realidade o torna um ser humano produtivo, fixando-o à sua terra, vivificando essa terra nas fronteiras e no interior, tornando o índio um brasileiro, um patriota e acima de tudo um símbolo da nossa soberania naquelas áreas tão desconhecidas e desligadas da nossa civilização. [...] tendo como resultado a transformação de malocas em povoados, em vilas e em cidades ${ }^{8}$.

O mesmo brigadeiro Protásio afirmou, em 1980, que “a Amazônia só será nossa quando habitada por brasileiros e não por índios que não têm nacionalidade".

Durante o governo José Sarney (1985-1990), o General Bayma Denis expressou a decisão do governo com relação às terras indígenas em faixa de fronteira: "Não serão demarcadas áreas indígenas na faixa de $150 \mathrm{~km}$ de largura a partir da linha de fronteira. Esta é uma posição pessoal e fechada do presidente José Sarney, que inclusive está ciente da ilegalidade de tal proceder" (Rubem Bayma Denys, $26 / 1 / 87)$.

Em 1986, divulgava-se que “o Conselho de Segurança Nacional não pretend[ia] demarcar áreas indígenas nos seguintes casos: 1. em faixa de fronteira; 2. tratando-se de áreas consideradas demasiado extensas; 3. áreas próximas a cidades; 4. áreas cortadas por estradas federais; 5 . áreas cortadas por rios" (nota do Cimi, Brasília 31 de outubro de 1986).

O pensamento militar, baseado na ideologia da segurança nacional, tem se atualizado e afirmado por meio de projetos como o Calha Norte. Mantém-se também através da legislação,como exemplifica o decreto 4.412/02, editado já no final do governo FHC (1995-2003), que assegura o trânsito livre das Forças Armadas e Polícia Federal nas áreas indígenas.

Esta política se materializa por meio da estratégia de inviabilizar as terras e os projetos de vida dos povos indígenas, através do povoamento e ocupação das mesmas por não-indígenas. Exemplo disso é a instalação do quartel em Uiramutã, como forma de garantir a invasão da terra indígena Raposa Serra do Sol, em Roraima. O projeto Calha Norte é projetado nessa perspectiva - ocupar e desenvolver as áreas de fronteira, através de quartéis, como núcleos de povoação.

O Governo Lula, ao contrário das expectativas iniciais dos povos indígenas, reforçou a presença militar nas decisões sobre o reconhecimento de terras indígenas em faixas de fronteira. 
$\mathrm{Na}$ tentativa de formular uma política indigenista [o governo federal] formou um Grupo de Trabalho (GT) sob a responsabilidade do Gabinete de Segurança Institucional, com forte influência de setores militares conservadores. Com esta decisão, passa a tratar da questão indígena como assunto da ultrapassada política de segurança nacional, considerando os povos indígenas como ameaça à soberania nacional quando, na realidade, fomos os responsáveis até hoje pela proteção das fronteiras e pela preservação ambiental de grande parcela da Amazônia brasileira, afirmam os indígenas no documento final do II Fórum Permanente dos Povos Indígenas da Amazônia, realizado em novembro de 2004, em Cuiabá.

Durante seminário sobre faixas de fronteira ocorrido em 2004, representante do Ministério da Defesa, Vice-Almirante Murilo Rego Barbosa, explicitou a posição daquele Ministério:

Quando consideramos que, para complementar ações das Forças Armadas na defesa nacional, precisamos da presença do brasileiro nas fronteiras do país, obviamente terras indígenas extremamente extensas e com muito baixa densidade demográfica não atendem aos interesses da defesa nacional. Este é o nosso ponto e entendemos que Raposa Serra do Sol poderia ser demarcada de outra forma, preservando todos os direitos dos índios e também atendendo às necessidades da defesa nacional, com a presença de atividades de desenvolvimento.

No mesmo seminário, o professor da Universidade Estadual de Campinas (Unicamp), Eliézer Rizzo de Oliveira, colocou opinião contrária:

Quero problematizar o conceito de despovoamento como perigo. Terras demarcadas fazem parte do território brasileiro e são questão de estratégia de chegar, não de exclusão. É menos uma questão de defesa nacional e mais uma questão societária, da relação entre os direitos indígenas definidos na constituição e as aspirações e necessidades da sociedade envolvente quanto à ocupação de terras,

disse o professor, que afirmou a necessidade de descriminalização da questão indígena.

Episódios recentes mostram que a presença indígena é benéfica à soberania e à segurança nacional. Foram os índios Ashaninka, do Acre, na fronteira Brasil-Peru, e com populações presentes nos dois países, que denunciaram a invasão por madeireiros e narcotraficantes peruanos. Foram também indígenas do Alto Rio Negro (AM) que solicitaram a destruição de pistas de pouso de garimpo.

Em relação à presença militar na Amazônia (e aqui nos referimos à Amazônia como um todo, não apenas ao território brasileiro) é notável também um processo de militarização regido pelas forças de segurança estadunidenses.

Acordos entre países latino-americanos e os EUA propiciam intervenções, exercícios e patrulhamentos militares, treinamentos de efetivos nacionais, insta- 
lação de radares, sistemas de vigilância e inteligência por meio de satélites e terrestres, quando não a instalação direta de bases militares em todo o continente. As ocupações e intervenções econômicas e militares, como o Plano Colômbia, o Plano Puebla, no Panamá, Plano Dignidade, TLCAN, Alca e Iniciativa Andina buscam impedir a insurgência, manter o domínio das grandes corporações sobre os recursos naturais e reger os destinos da região.

Essa questão foi objeto de reflexão e debate no Primeiro Encontro do Hemisfério frente à Militarização, realizado no México, em 2002. Entre suas conclusões, o encontro afirma que

a militarização leva a graves violações de direitos humanos, donde as mulheres são as maiores vítimas; destrói comunidades tradicionais dos povos indígenas; incrementa a migração forçada de milhões de pessoas; a destruição do meio ambiente; e a repressão dos movimentos populares e os processos democráticos e soberanos. Os povos lutamos pela vida, a militarização semeia a morte.

\section{Os povos livres}

Ao longo da história, numerosos povos indígenas optaram por se manter afastados da sociedade brasileira, em função de suas experiências traumáticas com as frentes de expansão nacional e as agências públicas. Essa estratégia de sobrevivência continua sendo usada por muitos povos na Amazônia. Esses povos são comumente chamados, de forma inadequada, de "isolados" ou "sem contato". Preferimos chamá-los de "livres" por não se sujeitarem a forma alguma de dominação. Não estão livres, no entanto, dos massacres, das epidemias e da usurpação de seus territórios. A história recente da Amazônia, por ocasião da abertura das estradas que apregoavam a integração nacional, é repleta de fatos que atestam como esses povos tiveram sua opção pela liberdade desrespeitada, sendo vítimas de enormes atrocidades. Contra eles foram usados modernas armas de fogo, gases tóxicos, arsênico misturado no açúcar e terríveis doenças epidêmicas. Nessa época, caso a ação de "pacificação" feita pelas agências do Estado não alcançasse os resultados esperados para retirar os "obstáculos do desenvolvimento", recorria-se à força das armas. É o que acontece com a abertura da BR 174, diante da defesa organizada dos Waimiri-Atroari de seu território. Entre 1968 e 1971, estima-se que dois mil índios foram mortos, seja pelas forças repressivas do Estado ou de mercenários a seu serviço.

O saldo dessa guerra desigual, ainda que não tenha representado o fim de todos os povos indígenas, deixou traumas profundos nos povos sobreviventes que, com a população reduzida e dispersa e o dinamismo sociocultural abalado, encontram grandes dificuldades para reconstruir sua identidade e seus projetos de vida.

Apesar do impiedoso processo de exploração capitalista, atualmente mais de quarenta povos indígenas procuram manter seus espaços de auto-suficiência na Amazônia. As informações sobre eles vêm de outros índios, da Funai, de missionários e também de pessoas que participam de expedições que invadem suas terras e encontram os índios ou vestígios deles. 
A partir dessas informações é possível deduzir que, na maioria das vezes, trata-se de grupos bastante reduzidos numericamente e que, em muitas situações, através do nomadismo, evitam o contato com os agentes da sociedade brasileira. Encontram-se hoje no limite da resistência, acossados por fazendas, garimpos e projetos de colonização. Sua segurança e sobrevivência são motivos de grande preocupação. Existem fortes suspeitas de que, nos últimos anos, muitos desses povos foram vítimas de brutais violações, inclusive com possibilidade de terem ocorrido massacres de povos inteiros. Por isso é necessária uma ação urgente por parte do Estado, notadamente no Mato Grosso, Rondônia e sul do Amazonas, para evitar que esses povos, no início do século XXI, sejam exterminados pelos agentes do "desenvolvimento", inimigos da floresta e de quem vive nela.

\section{Movimento e organizações indígenas na Amazônia}

A partir da década de 1970, acelerou-se o processo de penetração do sistema capitalista na região amazônica, estimulado e apoiado pelos projetos desenvolvimentistas dos diversos países da bacia. O Brasil inseriu-se neste contexto de forma marcante, através de seu "projeto de integração nacional", de colonização, construção de estradas, hidrelétricas, pelotões militares e pistas de pouso.

Este processo significou a diminuição e, por vezes, a extinção de grupos indígenas. Outros ainda foram levados à transferência forçada: para o Parque do Xingu, por exemplo, foram levados diversos povos. Nesse contexto, povos indígenas gestaram seu grito de resistência, organizaram-se e articularam ações contra a invasão e saque da terra e dos recursos naturais.

Desde o início dos anos de 1970 começaram, timidamente, a surgir formas novas de organização indígena, diferentes das organizações tradicionais de cada povo. Esse processo de organização de enfrentamento organizado teve um grande impulso com a realização da Primeira Assembléia dos chefes indígenas, que aconteceu em Diamantino, no Mato Grosso, em abril de 1974. Rapidamente foram acontecendo assembléias regionais e nacionais, inicialmente com maior intensidade na região amazônica.

$\mathrm{Na}$ década de 1980 multiplicaram-se as organizações por povos, regiões, atividades (professores, agentes de saúde, estudantes...), gênero, organizações de mulheres, por funções sociais (organização de caciques). Esse processo teve um ponto alto e estímulo nas conquistas na Constituição de 1988.

O processo de organização regional tem na Coiab - Coordenação das Organizações Indígenas da Amazônia Brasileira, um dos seus espaços de aglutinação e articulação. Hoje, a Coiab congrega mais de cem organizações indígenas, de 165 povos, organizada em 31 regiões. Apesar de ter passado por momentos de crise, particularmente após a Marcha e Conferência Indígena, em 2000, e dos convênios com a Fundação Nacional de Saúde a partir de 1999, atualmente a Coiab está em processo político ativo, realiza uma avaliação interna e amplia sua rede de aliados e parceiros na Amazônia e em todo o país. 
Em novembro de 2004, representantes de povos indígenas de toda a Amazônia, organizados através da Coiab, realizaram o II Fórum Permanente dos Povos Indígenas da Amazônia, com o objetivo de "definir propostas para a construção de um novo projeto etnopolítico a partir de nossos valores". O encontro debateu temas como sustentabilidade, saúde e educação indígenas, identidade cultural, além de "orientações gerais para o aperfeiçoamento dos mecanismos de representação e de tomada de decisão do movimento indígena da Amazônia no plano local, nacional e regional", segundo o documento final do Fórum.

Apesar dos avanços significativos na conquista e proteção dos territórios, novos desafios são colocados constantemente. Dentre eles podemos citar a ocupação política de espaços nos executivos e legislativos, particularmente locais e regionais (secretarias municipais ou estaduais, prefeituras, câmaras de vereadores), e instâncias do governo federal. Outro desafio colocado é o da reconstrução de um espaço articulador do movimento indígena nacional.

Na vastidão amazônica, alguns fóruns e articulações locais merecem destaque. Em Roraima, os indígenas participam do movimento Nós Existimos, criado para aproximar os setores do estado que sofrem com problemas de discriminação econômica e social. O movimento favorece a aliança entre povos indígenas, trabalhadores urbanos e rurais, sindicatos e desempregados da cidade. Lançado em janeiro de 2003 por organizações não-governamentais presentes no Fórum Social Mundial de Porto Alegre, o Nós Existimos busca fortalecer a luta dos grupos específicos por meio de atuações conjuntas, e trata de temas como a demarcação das terras indígenas, combate à corrupção e à impunidade, geração de emprego e renda e conservação ambiental.

O Fórum Amazônico Oriental (FAO) há mais de cinco anos aglutina indígenas, camponeses, ribeirinhos e o movimento de mulheres, entre outros, debatendo temas comuns. Há também dezenas de associações indígenas locais, como a Associação dos Povos Indígenas do Pará e Maranhão (Antapama).

\section{Fórum Social Pan Amazônico}

Há quatro anos, vem sendo realizado o Fórum Social Pan Amazônico, e o evento vem se tornado um importante espaço de articulação de movimentos sociais na região, ao reunir povos e organizações do Brasil, Bolívia, Peru, Colômbia, Equador, Venezuela, Guiana, Guiana Francesa e Suriname para a discussão de problemas comuns e para o estabelecimento de agendas conjuntas. $\mathrm{O}$ nível de organização dos movimentos sociais e também dos povos indígenas em cada um dos países desses povos difere muito, mas os temas se repetem: exploração de recursos naturais, militarização, a influência norte-americana na América Latina e os Tratados de Livre Comércio estão entre eles.

Em 2005, o Fórum Pan Amazônico ocorreu entre 18 e 22 de janeiro, em Manaus. Nesta edição, o desafio - para os povos indígenas e para os outros movimentos sociais - foi traçar linhas de ação em comum. A metodologia do Fórum 
incluiu encontros setoriais, onde os movimentos (indígena, afrodescendentes, mulheres, trabalhadores rurais, juventude etc.), reuniram-se para alinhavar as propostas de lutas conjuntas.

$\mathrm{O}$ documento produzido pelos indígenas neste encontro aponta para a importância da sociodiversidade dos povos, que continua sendo ameaçada pelo "modelo de desenvolvimento implementado pelos governos dos países amazônicos, submissos aos interesses de empresas transnacionais (petrolíferas, mineradoras, madeireiras, empreiteiras) e de setores oligárquicos interessados na exploração dos recursos naturais existentes nas terras indígenas". O documento tem ainda uma segunda parte, na qual os indígenas apresentam aos Estados Nacionais reivindicações que giram em torno do cumprimento dos direitos já conquistados legalmente, por meio das constituições dos Estados ou de acordos internacionais, como o Convenção 169 da Organização Internacional do Trabalho (OIT).

Entre do fim das ocupações militares em terras indígenas e a denúncia da omissão dos Estados Nacionais na consolidação dos direitos indígenas, fica clara a ainda conflituosa relação entre os governos dos países americanos e as populações tradicionais. Populações estas que reconhecem os Estados, sentem-se parte deles mas que - na Amazônia ou em qualquer outra região do continente - ainda buscam a construção de uma relação de respeito e, antes disso, de diálogo.

\section{Notas}

1 Agência de Notícias Estado, 3/4/2001 - Dirigentes de mais de dois milhões de indígenas que vivem na área de influência do rio amazônico Putomayo lançaram em Washington um apelo à comunidade internacional: "Ajudem-nos! O Plano Colômbia está nos aniquilando. Entre janeiro e maio de 2003, foram assassinados, na Colômbia, 106 indígenas. Os dados são de Amerigo Incalcaterra, diretor do escritório, na Colômbia, do Alto Comissionado das Nações Unidas para os Direitos Humanos, em seu discurso pronunciado durante a comemoração do Dia Internacional das Populações Indígenas, ocorrida no último dia nove (18.a go. 2003 - Colômbia-Adital/ Agenot).

2 Moreira Neto, Índios da Amazônia, de maioria a minoria, Petrópolis, Vozes, 1988.

3 Os dados que subestimavam a população indígena faziam parte da propaganda oficial, mostrando resultados da política integracionista, que previa o fim dos povos indígenas em 1998.

4 Apesar de esse fenômeno dos "índios resistentes" "“não somos ressurgidos nem emergentes, mas povos que resistiram", como eles se definiram num recente encontro nacional) ser inicialmente mais ligado à região nordeste do país, hoje temos casos expressivos na Amazônia. Um dos exemplos fica no baixo rio Tapajós, onde até há pouco tempo se dizia não mais existirem índios e, hoje, há mais de seis mil indígenas, pertencentes há mais de 5 povos, lutando dinâmica e criativamente pela sua terra e reconhecimento étnico.

5 Plano Distrital de Saúde, Convênio CIR, Boa Vista, Funasa, dez. 2001. 
6 Essa listagem foi elaborada pelo Conselho Indigenista Missionário - Cimi/ Secretariado Nacional. Brasília. Fontes: comunidades indígenas (informações repassadas para os regionais do Cimi), listagem da Funai de 19/9/04, ISA/96, Missão Tremenbé/ CE.

Denominações relativas às fases do procedimento demarcatório das terras indígenas:

1. "A identificar": terra com relatório do GT de identificação ainda não publicado no Diário Oficial da União (DOU) na forma do Decreto 1775/96.

2. "Identificada”: terra com relatório do GT de identificação publicado no DOU.

3. "Declarada": terra com Portaria Declaratória do Ministro da Justiça (Decs. 22 e 1775) ou Interministerial, além das portarias da Funai (quando for o caso).

4. "Homologada": terra demarcada e com Decreto de Homologação do Presidente da República.

5. "Registrada”: terra inscrita no Cartório de Registros de Imóveis da Comarca e no Departamento de Patrimônio da União. (conforme Art. 6ํ do Dec. 1775/96)

6. "Sem providências": são aquelas reconhecidas pelas comunidades indígenas e que não constam na listagem de terras da Funai

Modalidades de terra indígena:

1. "Tradicionalmente ocupada": terra ocupada de acordo com os usos, costumes e tradições indígenas, segundo o art. 231, $\$$ 1.ำ da Constituição Federal de 1988.

2. "Reservada": terra estabelecida a critério da União, em qualquer parte do território nacional, para servir à posse, ocupação e usufruto indígena, e que não se confundem com as terras tradicionalmente ocupadas (Lei 6.001/73, art. 26)

3. "Dominial indigena": terra de propriedade plena da comunidade ou do indivíduo indígena, segundo as formas de aquisição de domínio previstas na legislação civil (Lei 6001/ 73 , art. 32).

7 Consideramos, para este estudo, as terras indígenas localizadas em toda a extensão dos nove estados que compõem a Amazônia legal.

8 Declaração de Protásio Lopes de Oliveira durante um simpósio nacional sobre a Amazônia, realizado na Câmara dos Deputados em 1979 - texto da taquigrafia daquela casa.

Bibliografia

ALMEIDA, Alfredo Wagner Berno de. Carajás: a guerra dos mapas. Belém, Farangola, 1994.

ANDERSON, Anthony et al. O destino da floresta. Rio de Janeiro, Relume Dumará, 1994.

CASTRO, Eduardo Viveiros de Castro e CUNHA, Manoela Carneiro da (orgs.). AMAZÔNIA - Etnologia e História Indígena. São Paulo, NHII/USP, 1993.

CIMI - Conselho Indigenista Missionário. Marcha e Conferência Indígena. Brasília, Cimi, 2000.

Outros 500: construindo uma nova história. São Paulo, Salesiana, 2001. 
COSTA, Eugênio Pacelli Lazzarotti Diniz. O Projeto Calha Norte: antecedentes politicos. Dissertação de Mestrado, São Paulo, FFLCH-USP, 1994.

Direitos Humanos no Brasil 2001: Relatório da Rede Social de Justiça e Direitos Humanos em parceria com Global Exchange. São Paulo, Global Exchange, 2001. 2002 e 2003.

NETO, Moreira. Índios da Amazônia, de maioria a minoria. Petrópolis, Vozes, 1988.

OLIVEIRA, Ariovaldo Umbelino de. Amazônia: monopólio, expropriação e conflitos. Campinas, Papirus, 1989.

Porantim. Periódico Mensal. Brasília, Cimi.

PREZIA, Benedito (org.). Caminhando na luta e na esperança-Retrospectiva dos últimos 60 anos da Pastoral Indigenista e dos 30 anos do Cimi. São Paulo, Loyola, 2003.

SABATINI, Silvano. Massacre. São Paulo, Loyola, 1998.

Irmãzinhas de Jesus. O renascer do povo Tapirapé: diário das Irmãzinhas de Jesus De Charles de Foulcauld. São Paulo, Salesiana, 2002.

RESUMO - CERCA DE 180 povos indígenas vivem na região amazônica do Brasil, somando uma população de aproximadamente 208 mil indivíduos. São povos com as mais diversas situações de relação e contato com as sociedades não indígenas, marcadamente ocidentais e européias. Ali vivem desde povos resistentes (também chamados ressurgidos) até os povos livres (isolados, que não têm contato algum com as sociedades nacionais). Este texto aborda a presença indígena na região, o movimento indígena e a relação dos povos com o Estado brasileiro, responsável pela demarcação das terras tradicionalmente indígenas. Aborda-se também a relação com os setores que têm interesses econômicos na região e com setores militares, contrários à demarcação de terras em faixas de fronteira. O texto apresenta, como exemplo desses conflitos, a não-homologação da terra indígena Raposa Serra do Sol, em Roraima.

ABSTRACT - APPROXIMATELY 180 indigenous peoples inhabit Brazil's Amazon region, totaling a population of approximately 208,000 individuals. These peoples face highly variegated situations in terms of their relationship and contact with non-indigenous societies, notably Western and European, ranging from the so-called resistant peoples (also called resurgent) to free peoples (isolated, with no contact at all with national societies). This text discusses the indigenous presence in the region, the indigenous movement, and the relationship between the indigenous peoples and the Brazilian State, which is responsible for the demarcation of lands that traditionally belonged to native populations. It also comments on their relationship both with groups that have economic interests in the region and with the military, who oppose the demarcation of land near the country's frontiers. As an example of this conflict, the text mentions the non-homologation of the indigenous land Raposa Serra do Sol, in Roraima.

Palavras-chave: Amazônia, Povos Indígenas, Raposa Serra do Sol.

Key words: Amazon, Native Brazilian Peoples, Raposa Serra do Sol.

Egon Heck e Francisco Loebens fazem parte do Cimi - Conselho Indigenista Missionário, e Priscila D. Carvalho é assessora de comunicação da entidade.

Texto solicitado aos autores. Recebido e aceito para publicação em 26 de janeiro de 2005. 


\section{Anexo \\ Outra Amazônia é possível! \\ IV Fórum Social Pan Amazônico \\ Diversidade, Soberania e Paz \\ Manaus, Amazonas, Brasil, 18 a 22 de janeiro de 2005 \\ Amazônia Indígena}

Nós, povos, organizações, lideranças indígenas, instituições e movimentos aliados da causa indígena, reunidos por ocasião do IV Fórum Social Pan Amazônico Diversidade, Soberania e Paz -, a partir do intercâmbio das nossas realidades e experiências, constatamos:

A impressionante sociodiversidade existente na Amazônia é marcada pelas experiências históricas de povos milenares, que resistem às investidas do neoliberalismo, contribuindo dessa forma significativamente para a proteção das diferentes formas de vida nela existentes.

A contribuição dos povos indígenas está sendo gravemente ameaçada pelas ações predatórias decorrentes do modelo de desenvolvimento implementado pelos governos dos países amazônicos, submissos aos interesses de empresas transnacionais (petrolíferas, mineradoras, madeireiras, empreiteiras) e de setores oligárquicos interessados na exploração dos recursos naturais existentes nas terras indígenas.

Os grandes projetos ameaçam a continuidade física e cultural dos povos indígenas, ao destruírem o seu hábitat, a sua cultura, e os recursos naturais necessários para sua existência.

Os Estados Nacionais amazônicos, a pesar de terem Constituições que na sua maioria reconhecem os direitos dos povos indígenas, na prática adotam políticas que afrontam esses direitos, chegando em muitas ocasiões a considerarem os povos indígenas como ameaças à soberania.

Os Estados Nacionais têm sido omissos, coniventes e às vezes responsáveis diretos por atos de violência contra os povos indígenas, tal como acontece na Colômbia, onde estes são vítimas da guerra infinita patrocinada pelo governo norteamericano, através do Plano Colômbia.

As fronteiras dos Estados Nacionais significaram a violenta divisão de muitos povos e culturas milenares da Amazônia, impedindo até hoje o seu livre trânsito nos seus territórios tradicionais.

A falta de regularização e proteção das terras indígenas constitui um incentivo aos invasores, gera conflitos e revela a falta de compromisso dos diferentes governos com a existência futura desses povos enquanto sujeitos históricos detentores de direitos e portadores de identidades e culturas distintas.

Face a essa situação, reivindicamos:

Que os governos ponham fim à ocupação militar, retirando as bases militares instaladas nos territórios indígenas, como a base Molino de Sarayacu, no Equador, e a base de Uiramutã, em Roraima, Brasil. 
Que o governo da Colômbia ponha fim à invasão do imperialismo norteamericano e o Plano Colômbia, criando condições para uma solução negociada do conflito armado interno.

Que o governo equatoriano cumpra as medidas cautelares, relacionadas com a integridade territorial e cultural, outorgadas em favor do povo Quíchua de Sarayacu e de suas lideranças, pela Comissão Inter-americana de Direitos Humanos.

Que o governo brasileiro viabilize, com a ampla participação dos povos indígenas, a formulação e implementação de uma nova política indigenista, a regularização de todas as terras indígenas e que decrete imediatamente a homologação da Terra Indígena Raposa Serra do Sol.

Que os governos dos países da Amazônia não coloquem empecilhos para o livre trânsito de povos indígenas irmãos localizados nas regiões fronteiriças dos Estados Nacionais.

Que os governos garantam a participação dos povos indígenas na discussão dos projetos e decisões que os afetem, em conformidade com a Convenção 169 da Organização Internacional do Trabalho (OIT).

Que os organismos internacionais dos distintos Estados e da sociedade civil organizada estejam atentos às políticas anti-indígenas dos governos e se mobilizem para resguardar os direitos dos povos amazônicos, principalmente indígenas.

Manifestamos a nossa solidariedade aos povos da Amazônia agredidos, em especial aos povos indígenas da Colômbia vitimados pela guerra, e à luta dos trabalhadores e trabalhadoras rurais e da cidade.

Afirmamos a nossa disposição de fortalecer e unificar as nossas lutas com todos aqueles que acreditam, sonham e contribuem para a construção de uma sociedade onde a vida, e os diferentes povos e culturas sejam respeitadas.

Manaus, 22 de janeiro de 2005. 